\title{
Use of X-ray Micro-CT to characterize structure phenomena during frying
}

T. Miri, S. Bakalis, S. D. Bhima and P. J Fryer

Centre for Formulation Engineering (Chemical Engineering), University of Birmingham, Edgbaston, Birmingham, B15 2TT, United Kingdom

s.t.mirishaktaee@,bham.ac.uk

It is the microstructure that gives the desired textural characteristics to food products. Thus it is of our interest to understand structuring mechanisms in order to be able to design food products with specific textural properties. Furthermore, in the case of frying, consumers demand for healthier foods has initiated interest in understudying the underlying physical phenomena of oil absorption during frying. A number of techniques have been used to quantify internal structures of fried foods (e.g. optical microscopy, confocal laser scanning microscopy, Bouchon et al., 2001) but there is a need of methods that would allow detailed $3 \mathrm{D}$, non-invasive quantitative characterization of food microstructures. Recently X-ray microcomputed tomography (X-ray micro-CT) has been introduced as a new method to investigate food structures (Mousavi et al., 2005). X-ray micro-CT is a combination of X-ray microscopy and tomographical algorithms that can resolve details as small as a few microns in size. It is based on differences in X-ray attenuation (absorption and scattering) arising principally from differences in density within the specimen.

In this work the effect of frying time and frying temperature on the structure of potato strips was investigated. Three dimensional images of samples at different frying times and temperature were obtained. It was also possible to quantify parameters such as pore size distribution and crust development during frying. This work demonstrates the capabilities of $\mathrm{X}$-ray micro-computed tomography as a non-invasive technique for the study of the internal $3 \mathrm{D}$ microstructure of food materials and relate it to processing parameters in a way that allows not only a fundamental understanding of the process but also a process design that would result in specific microstructures. 


\section{Introduction}

It is the microstructure of foods that gives the desired attributes to various products (Aguilera, JM 2005; Aguilera, JM 2006; Norton, I and others 2006). It has been also argued that provide immense capabilities in designing novel products that would improve our health. (Norton, I and others 2006). In this work we are interested in the microstructure creation during frying. Deep-fat frying of potatoes can be defined (Miranda, ML Aguilera, JM 2006)) as the process of cooking foods by immersing them in an edible oil or fat which is at a temperature above the boiling point of water, typically $150-200 \mathrm{oC}$. Upon addition of the French fries to the hot oil, the surface temperature of the fries rises rapidly. The water at the surface of the fries immediately starts boiling, the surrounding oil is, in the process, cooled to lower temperatures, but this is only a temporary effect as it is quickly compensated by convection. In the event that the amount of added French fries exceeds a critical value, only then will the temperature of the oil be significantly affected (Mellema, 2003). As the boiling commences, the convection will be further intensified by the turbulent water vapour; due to the evaporation, surface drying will occur along with shrinkage and the development of surface porosity and roughness. Mellema (2003) also adds that explosive evaporation can lead to the formation of large pores. As frying time increases moisture content in the crust decreases, thereby reducing the amount of steam leaving the surface. In some circumstances, the surface temperature may rise above the boiling point of water, but it is to be noted that for several large pieces of food such (e.g. meat balls and French fries) the temperature of the core most probably will not go above that point (Mellema, 2003). Several physico-chemical changes also take place, such as starch retrogradation, Maillard reactions and glass transitions, and this will lead to organoleptic properties and colour of the crust.

One of the important issues during frying is related to oil absorption which occurs during frying and more importantly during the subsequent cooling of the final product. The fat content of a deep fried product is typically $33 \%$ for potato chips and $14 \%$ for French fries (Mellema, M 2003), which in many cases promotes the palatability. Oil absorption occurs his effect is more evident when small pores are formed in the crust, Moreira et al (1997) have found that the narrower the pores the larger will be the fat intake, so that this process is expected to occur at higher temperatures and at higher frying times when it is the most probable conditions for small pores to be formed

Quantification of oil uptake and its specific sites can be done via the solvent extraction method - The Soxhlet method (Pinthus et al, 1992; Kozempel et al, 1991; Lamberg et al, 
1990) Differential Scanning Calorimetry has been used as an alternative approach to study the oil uptake during the frying (Aguilera \& Gloria, 1997), demonstrating that the amount of fat in the crust is six times greater than that in the core (Aguilera \& Gloria, 1997). Moreira et al., 1997 reported that for tortilla chips narrow pores lead to more fat uptake than wide pores, for radii smaller than $1 \mathrm{~mm}$, the capillary pressure can lead to fat uptake even if the pores are filled with vapour. Pore depth determines the maximum depth of oil penetration.

The structure of French fries is in general characterised by two regions (Moreira et al, 1999): a crispy crust (surface layer) of about $1-2 \mathrm{~mm}$ thick where most of the absorbed frying oil is located, and a soft crumb (interior), and they have been traditionally prepared by batch frying the potatoes twice - once to cook, and once to crisp. As the frying proceeds the interface will move more and more deeply into the structure of the French fries. During the frying process the moisture inside the French fries will evaporate and leave the food due to a positive pressure difference, oil will then enter the food at the damaged parts and fill the pores left open. This process is restricted during the frying process to the outside (surface) layer, but the interface as previously mentioned will move deeper into the food as the frying time is lengthened. This seems to be a slow process as most of the oil is absorbed by the potato chip during the cooling period rather than during the frying process.

In this paper a novel non invasive non destructive technique will be used to quantify the microstructure of French fries X-ray Micro-Computed Tomography, X-ray Micro-CT for short. X-ray Micro-CT has been used in medical research on bone and teeth structures (Patel et al, 2003) and in the characterisation of metallic foams, biomaterials, and even in the anatomic definition of parts of the human ear (Lane et al, 2003). It can thus be used for the imaging of the microstructure of small samples like French fries.

In micro-CT a tomographic scan is accomplished by rotating the specimen about an axis perpendicular to the X-ray beam while collecting radiographs of the specimen at small angular increments (0.9 degree). The radiographs are then reconstructed into a series of 2-D slices The series of slices, covering the entire sample, can be rendered into a 3-D image that can either be presented as a whole or as virtual slices of the sample at different depths and in different directions. Manipulation of Micro-CT data using special software also allows reconstruction of cross-sections at depth increments as low as 15 micrometre, and along any desired orientation of the plane of cut. A series of non-invasive micro-CT slices of the same sample in any direction can provide much more information than just one Scanning Electron Microscopy or optical imaging picture for example. The true 3-D shape of the cells can also be visualized from its 2-D slices. It is clear from the above discussion that micro-CT is an 
important tool that holds great potential for imaging biopolymeric or food foam structures (Trater et al, 2005). Recently X-ray micro-CT has been used as means to quantify microstructures in foods (Mousavi, R et al, 2005).

\section{Materials and methods}

The materials used in this work are as follows :

Potatoes were obtained from a local suppler and were cut in cylindrical shapes having diameters $11.5 \mathrm{~mm}$ and length of $40 \mathrm{~mm}$ (length $>$ diameter). Samples were consecutively fried using a mixture of vegetable oils under the trade name 'Crisp N Dry' in a 'Cordon Bleu DF-2102CB' fryer. Frying process was performed at the temperatures of 160,170 and $180^{\circ} \mathrm{C}$, and for frying times of 2, 3, 5 and 7 minutes.

$\mathrm{X}$-ray micro-computed tomography samples were scanned using a high-resolution X-ray micro-CT system, Skyscan 1072 (Skyscan, Belgium) at a voltage of 100V, $96 \mu \mathrm{A}$. The bread samples were cut using a cylindrical bore-hole with diameter of $1 \mathrm{~cm}$ and height of $2 \mathrm{~cm}$. The samples were scanned in their native environment conditions without any special preparation. Samples were placed onto a holder using double sided tape to avoid movement, and then placed into the Skyscan machine.

For micro-tomographical reconstruction, X-ray images were acquired from up to 400 views through 180 degrees of rotation of the sample. These X-ray images are commonly called shadow images and are essentially projections of the sample to the X-ray sensor. The scanning process is controlled by Skyscan internal software, which also allows microtomographical reconstruction using the shadow images.

\section{Results and Discussion}

Frying is a complex process that involves chemical reactions, heat and mass transfer as well as creation of a complex microstructure. The objective of this work is to use and develop a novel non invasive, non destructive technique that allows characterization of microstructure. In Fig. 1 photograph of raw samples (a) and that after frying at $170^{\circ} \mathrm{C}$ for $5 \mathrm{~min}(\mathrm{~b})$ are shown. It can be seen that fried samples experiencing shrinkage and colour development is not uniform. Thus although conventional techniques can identify changes they can result in information limited in the surface of the sample. It is possible to slice sample to obtain information about the crust and internal structure, but the resulting artefacts affect the 
accuracy of information obtained. Therefore application of X-ray Micro-CT can be beneficial since 3D details about the microstructure can be obtained.

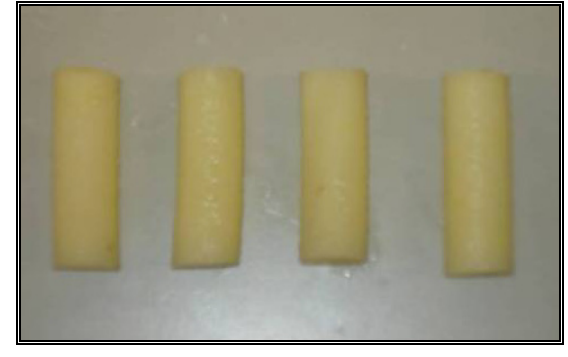

(a)

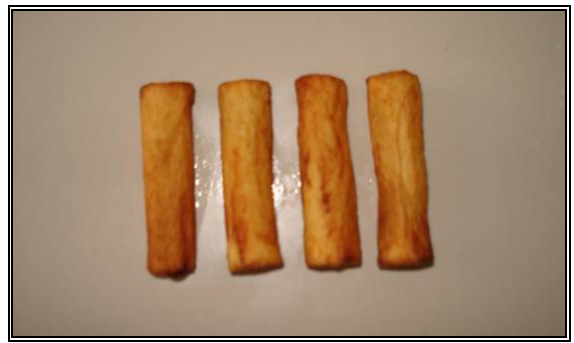

(b)

Fig. 1 Images of (a) raw and (b) fried potato samples at $170{ }^{\circ} \mathrm{C}$ for $5 \mathrm{~min}$

Fig. 2 shows a shadow image of sample fried at $170^{\circ} \mathrm{C}$ for 5 min obtained using the X-ray Micro-CT. Sample had an original diameter of $11.5 \mathrm{~mm}$. Darker areas are areas were X-rays are more absorbed, indicating denser structures. Although the shadow image is considered as raw data, the porous structure of the crust developed in the outer rim of the sample can be seen as light gray areas.

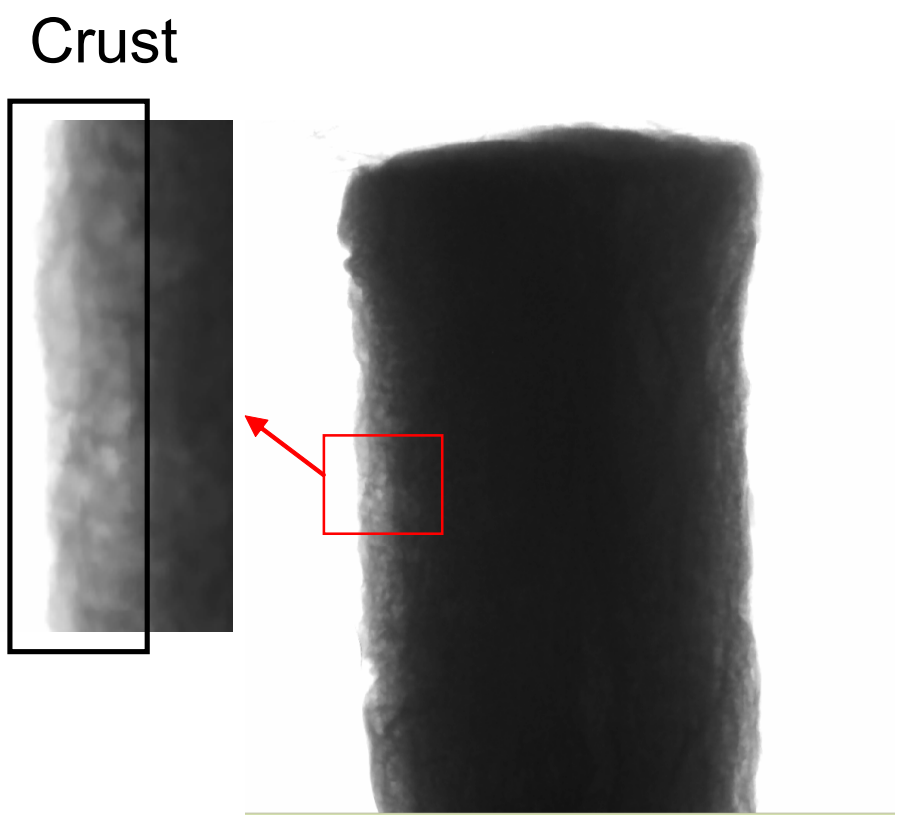

Fig. 2. Shadow image obtained using the X-ray Micro-CT of sample fried at $170^{\circ} \mathrm{C}$ for $5 \mathrm{~min}$ having an original diameter of $11.5 \mathrm{~mm}$. 
From the shadow images the cross-section of a sample can be reconstructed using specially developed algorithms. In Fig.3 (a) reconstructed cross-sectional images of a sample fried at $170^{\circ} \mathrm{C}$ for $5 \mathrm{~min}$ is shown. Using a dedicated image analysis software (Skyscan) areas of interest can be isolated for further analysis. In Fig.3 (b) only the crust of the sample is shown as a porous area consisting of many small air cells. As it appears from these images the air cells in the crust are closed, i.e. not interconnected. Furthermore, the crust developed in an irregular non uniform manner. During frying as a result of decreasing water content, sample density decreases. Therefore after 3-5 min sample rise to the surface of the oil. This can result in non uniform heat and mass transfer rates, hence the non uniform crust formation. It has to be kept in mind though that crust formation is random in nature this can result in non uniform structures.

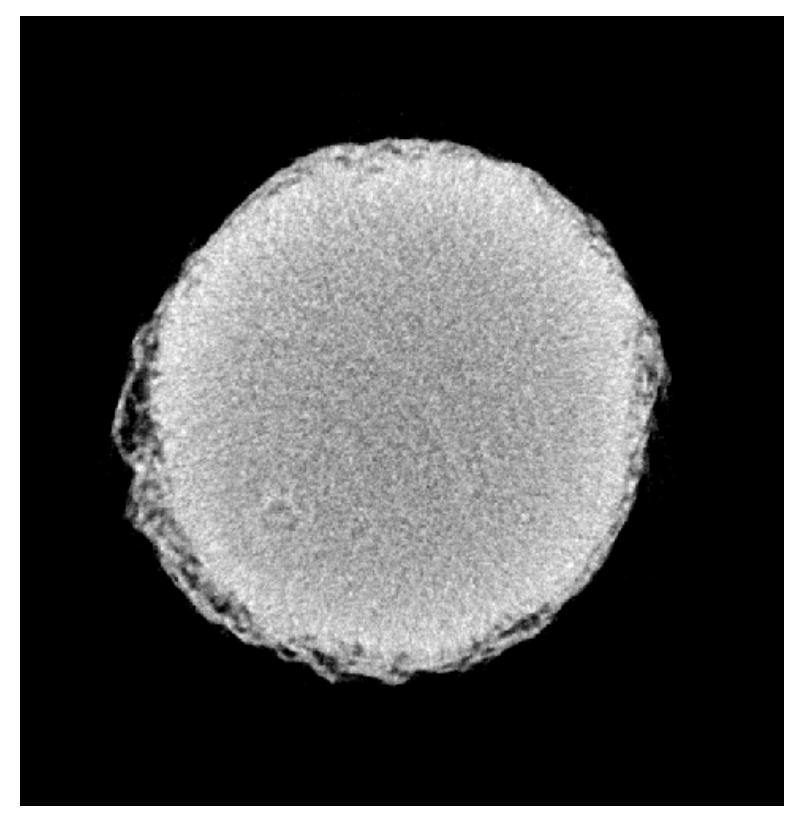

(a)

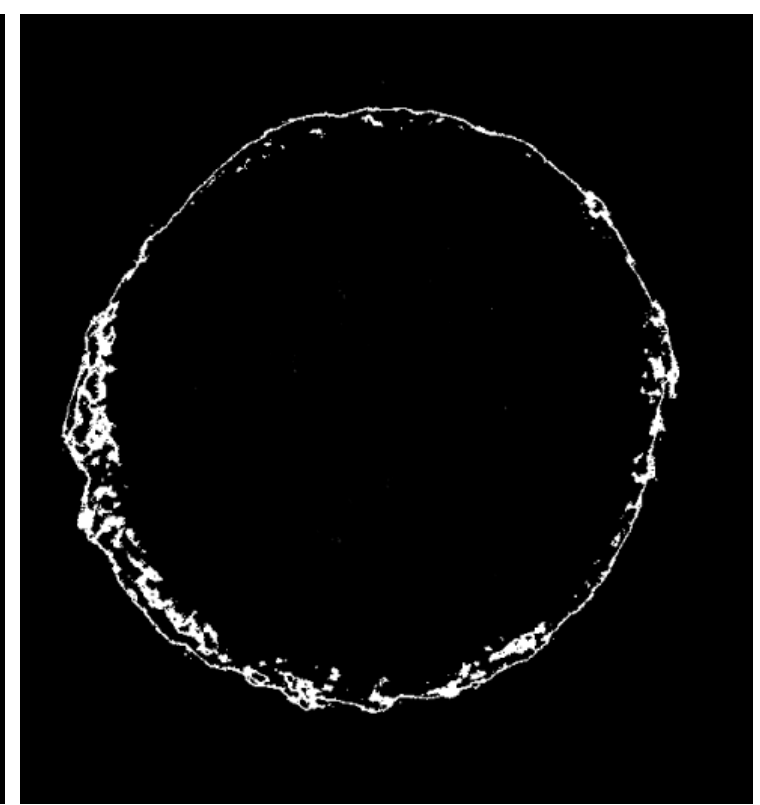

(b)

Fig.3 Reconstructed cross-sectional images of samples fried at $170^{\circ} \mathrm{C}$ for $5 \mathrm{~min}$ having an original diameter of $11.5 \mathrm{~mm}$ (a). The crust of the sample is shown in (b) 
Fig.4 shows (from left to right) cross-sectional images of samples fried for 2, 3, 5 and $7 \mathrm{~min}$ at $170^{\circ} \mathrm{C}$. One should keep in mind that these cross-sections are not from the same sample, but are representative of the microstructures. The lighter areas in the circumference of the samples correspond to the crust as it is formed. As it can be seen the crust slowly moves inwards towards the centre of the sample. It is also important to note that dramatic changes in the structure occur between the 5 and 7 min of frying.

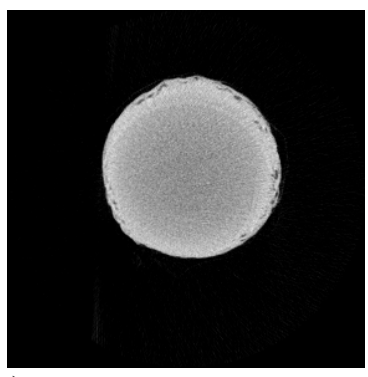

(a)

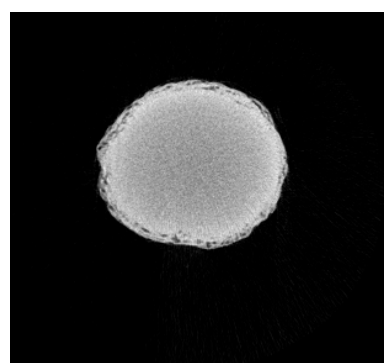

(b)

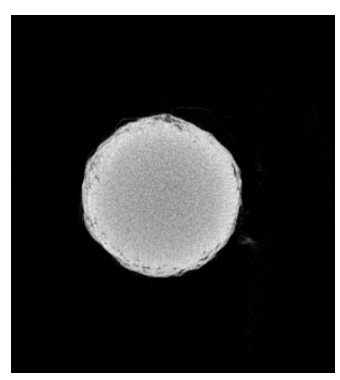

(c)

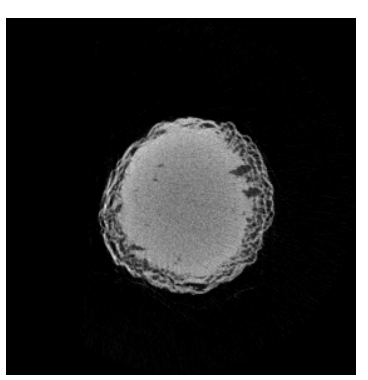

(d)

Fig. 4. Reconstructed cross sectional images of samples fried at $170^{\circ} \mathrm{C}$ having an original diameter of $11.5 \mathrm{~mm}$ for 2 (a), 3 (b), 5 (c) and 7 mins (d)

In Fig. 5. a cross-sectional image of samples fried at $160^{\circ} \mathrm{C} 7 \mathrm{~min}$ is shown. Similarly to the previous cross-sections a porous crust can be identified in the surface of the sample. Furthermore void areas can be seen within the sample matrix. This can be a result of steam entrapped in the samples during frying. 


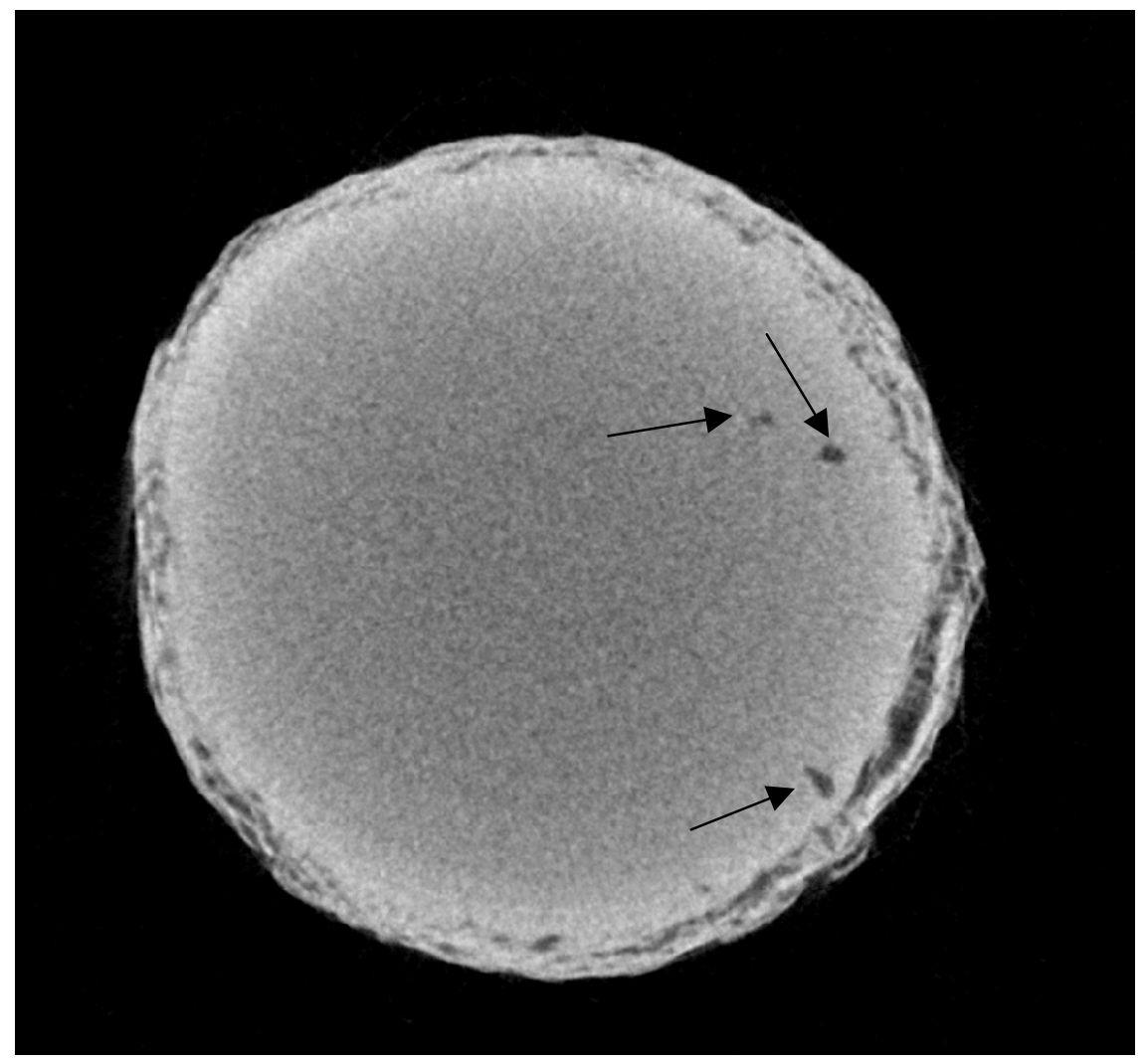

Fig. 5. Reconstructed cross sectional images of samples fried at $160^{\circ} \mathrm{C} 7 \mathrm{~min}$ showing a void area inside the sample.

In Fig. 6 a cross-sectional image of a sample fried at $180{ }^{\circ} \mathrm{C}$ for $7 \mathrm{~min}$ is shown. The microstructure of the crust in this case is more pronounced. Not only the crust has penetrated deeper into the sample but also the air cells are much bigger in size. Additionally the cells appear to be aligned with the circumference of the sample. 


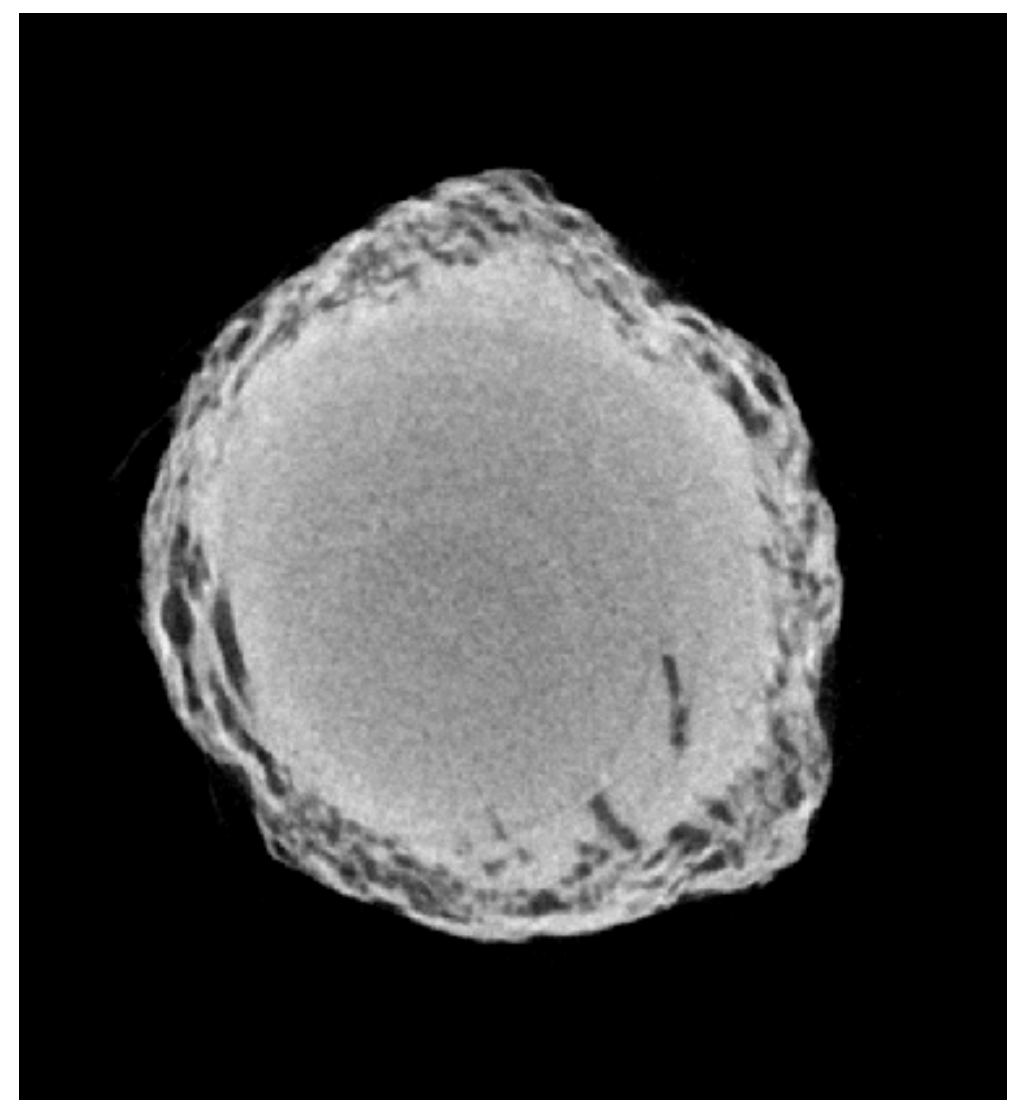

Fig. 6. Reconstructed cross sectional images of samples fried at $160^{\circ} \mathrm{C} 7 \mathrm{~min}$

The three dimensional structure can be reconstructed using the two dimensional cross-sections. A snapshot of 3-D model of a sample fried at $170 \mathrm{C}$ for $7 \mathrm{~min}$ is shown in Fig 7 in which $1 / 4$ of the model virtually cut-off to reveal the internal structure and the depth of crust. The non uniform structure of the crust becomes apparent from this model. 


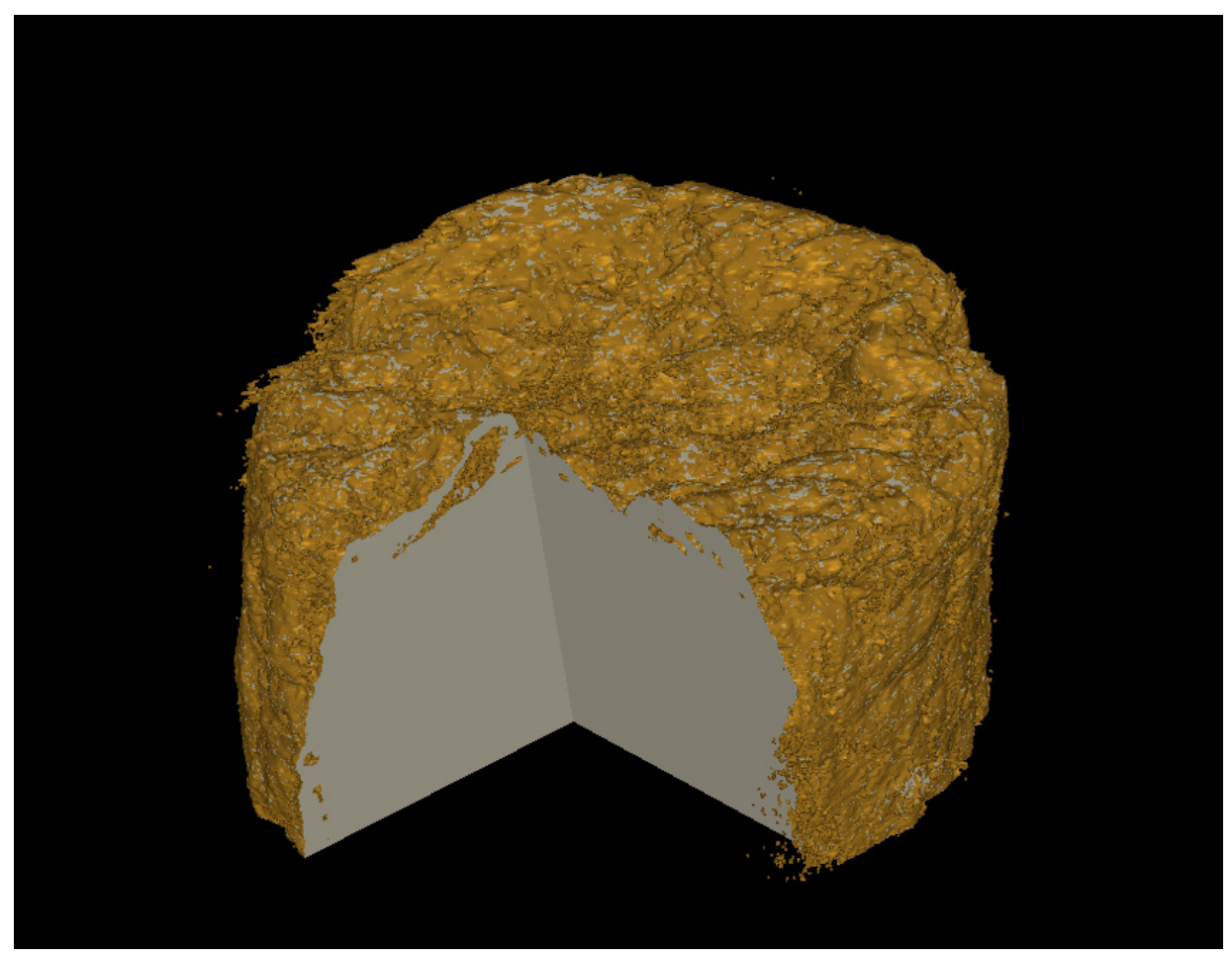

Fig. 7 3-D model of sample, fried at 170C for $5 \mathrm{~min}$

Using two dimensional cross-sections, similar to those presented in Figs 2-6 it is possible to obtain pore size distributions of the samples. In Fig 8 the pore size distributions in sample fried at 180 for 7 min based in area (a) and number (b) are shown. From Fig. 8 (a) one can see that there is a wide distribution of pores sizes from a few $\mu \mathrm{m}$ to $\mathrm{mm}$. There are only a few larger pores that contribute significantly to the void area. This might be of significance to the amount of oil absorbed from the fried samples after frying. 


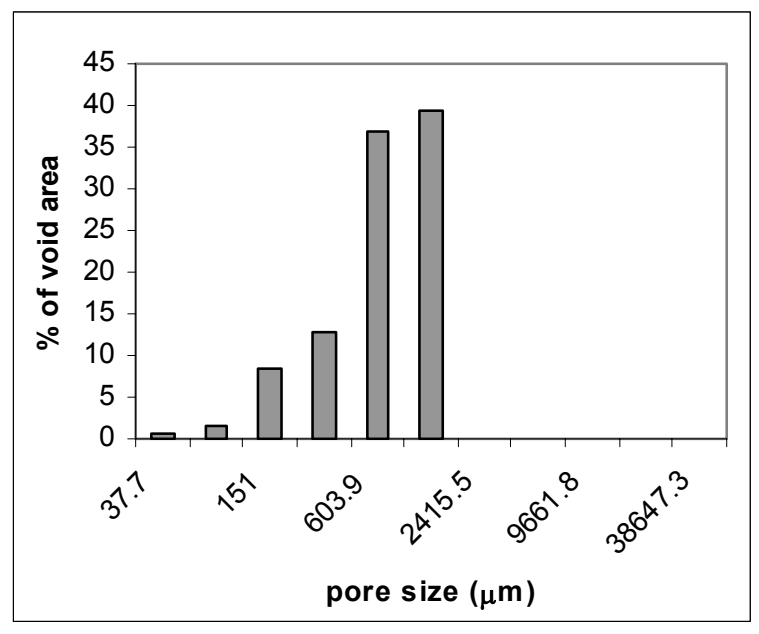

(a)

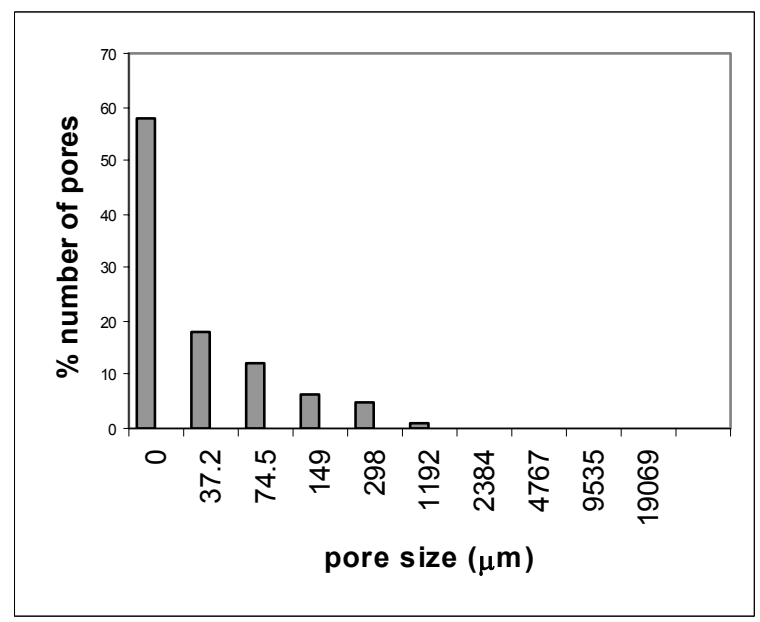

(b)

Fig. 8 Pore size distribution in sample fried at 170 for $5 \mathrm{~min}$ based on area (a) and numbers of pores (b).

From the obtained images the crust sizes can be measured at various steps of the frying process (Table 1). As it was previously mentioned the crust is not formed uniformly along the sample. Thus, for each sample a range of crust sizes is recorded rather than a single value. As it was expected crust size increases with frying time and temperature. For both processing temperatures the crust size becomes significant, i.e. larger than $500 \mu \mathrm{m}$ after $5 \mathrm{~min}$ of processing.

Table 1. Measured crust size for different frying conditions

\begin{tabular}{|c|l|l|}
\hline \multirow{2}{*}{ Frying Time $(\mathrm{min})$} & \multicolumn{2}{|c|}{ Crust size $(\mu \mathrm{m})$} \\
\cline { 2 - 3 } & frying at $180^{\circ} \mathrm{C}$ & frying at $170^{\circ} \mathrm{C}$ \\
\hline 2 & 300 & 100 \\
\hline 5 & $300-600$ & $100-500$ \\
\hline 7 & $700-1000$ & $100,500-700$ \\
\hline
\end{tabular}




\section{Conclusions}

A number of techniques have been used to characterize the microstructure of potato samples during frying. In this work an X-ray Micro-CT a novel non invasive technique has been used to characterize the microstructure. It was possible to obtain a detailed characterization of the microstructure. The images obtained reveal the porous nature of the crust consisting of a few larger pores that contribute significantly to the void area, while limiting interconnectivity between the pores was observed. Furthermore the crust appeared to be formed non uniformly. It was also possible to measure crust size, crust increased with temperature and frying time. Overall this paper demonstrates the ability of this X-ray Micro-CT to be used in characterising complex food structures.

\section{References}

Aguilera, JM. 2005. Why food microstructure? Journal of Food Engineering 67(1-2):3-11.

Aguilera, JM. 2006. Seligman lecture 2005. Food product engineering: Building the right structures. Journal of the Science of Food and Agriculture 86(8):1147-55.

Aguilera, JM, Cadoche, L, Lopez, C, Gutierrez, G. 2001. Microstructural changes of potato cells and starch granules heated in oil. Food Research International 34(10):939-47.

Aguilera J.M, Gloria H. 1997. Determination of oil in fried potato products by differential scanning calorimetry, J. Agric. Food Chem, 45:781-785.

Bouchon P., Aguilera J.M. 2001. Microstructural analysis of frying potatoes. International Journal of Food Science \& Technology, 36:1-8.

Kozempel M.F, Tomasula P.M \& Craig P.M, 1991. Correlation of moisture and oil concentration in French fries, Food Science Technology (London), 24:445-448.

Lamberg I, Hallstroem B, Olsson H, 1990. Fat Uptake in a potato drying/frying process, Lebensm.-Wiss. Technol., 23:295-300.

Lane J.I et al, 2004. Imaging microscopy of the middle and inner ear Part I: CT Microscopy, Clinical Anatomy, 17:607-612.

Lim, KS, Barigiou, B. 2004. X-ray micro-tomography of cellular food products. Food Res Int 37:1001-12.

Mellema, M. 2003. Mechanism and reduction of fat uptake in deep-fat fried foods. Trends in Food Science and Technology 14(9):364-73. 
Miranda, ML , Aguilera, JM. 2006. Structure and texture properties of fried potato products. Food Reviews International 22(2):173-201.

Moreira R.G, Sun X.Z, \& Chen Y.H, 1997. Factors affecting oil-uptake in tortilla chips in deep-fat frying, Journal of Food Engineering, 31:485-498.

Moreira R.G, Castell-Perez M.E \& Barrufet M.A, 1999. Deep Fat Frying Fundamentals and Applications, Aspen Publishers Ltd, ISBN: 0-8342-1321-4.

Mousavi, R, Miri, T, Cox, PW, Fryer, PJ. 2005. A novel technique for ice crystal visualization in frozen solids using x-ray micro-computed tomography. Journal of Food Science 70(7):E437-E42.

Norton, I, Fryer, P, Moore, S. 2006. Product/process integration in food manufacture: Engineering sustained health. AIChE Journal 52(5):1632-40.

Patel V et al, 2003. MicroCT evaluation of normal and osteoarthritic bone structure in human knee species, Journal of Orthopaedic Research, 21:6-13.

Pinthus E.J, Weinberg P, Saguy I.S, 1992. Gel strength in restructured potato products affects oil uptake during deep-fat frying, Journal of Food Science, 57:1359-1360.

Trater A.M, Alavi S \& Rizvi S.S, 2005. Use of non-invasive X-ray microtomography for characterising microstructure of extruded biopolymer foams, Food Research International, 38:709-719. 